\title{
Integrating societal concerns into research and development (R\&D) on geological disposal at the national level
}

\author{
Meritxell Martell ${ }^{1, *}$ and Kris Van Berendoncks ${ }^{2}$ \\ 1 Merience SCP, Spain \\ 2 University of Antwerp, Prinsstraat 13, 2000 Antwerpen, Belgium
}

[Received 30 October 2014; Accepted 9 September 2015; Associate Editor: Nick D. Bryan]

\section{ABSTRACT}

The European InSOTEC project aims to identify remaining socio-technical challenges for the implementation of geological disposal of radioactive waste in European countries. Geological disposal has been recognized as the reference solution in radioactive waste management by the European Commission, which has set up the IGD-TP as a platform to foster exchanges between authorities on research and development (R\&D) on this topic. This paper turns to the national level to analyse national R\&D programmes on radioactive waste management (RWM) and particularly, geological disposal (GD) in order to assess to what extent there are national platforms that broaden interaction beyond an expert community. For this, we focus on identifying those practices and structures that reflect a degree of inter- and transdisciplinarity in the design and implementation of national R\&D programmes. Our argument, embedded in the Science and Technology Studies (STS) literature, is that the way GD is framed by the research and policy community has important implications for the processes of developing and governing a technology. From our empirical case studies, we will explore the extent to which social-science research is integrated and the way stakeholders may have an impact on the development of R\&D programmes. Overall, including social science research as an integral part in $R \& D$ programmes on GD and fostering collaboration between different types of knowledge in the R\&D agenda-setting phase may help in the consideration of GD as a socio-technical problem, where the social and the technical are inextricably linked.

KEYWORDs: cross-disciplinary, transdisciplinary, IGD-TP, radioactive waste management, geological disposal.

\section{Introduction}

Geological disposal has been recognized as the reference solution by the European Directive 2011/ 70/Euratom establishing a Community framework for the responsible and safe management of spent fuel and radioactive waste. The Directive states technical consensus as its basis: "It is broadly accepted at the technical level that $[\ldots]$ deep

*E-mail: meritxell.martell@merience.com DOI: $10.1180 /$ minmag.2015.079.6.31 geological disposal represents the safest and most sustainable option as the end point of the management of high-level waste and spent fuel considered as waste". As a consequence, it urges Member States to develop and implement national programmes for the management of all spent fuel and radioactive waste under their jurisdiction, including disposal as the final stage in the management of radioactive materials (Article 11 [1]). This suggests that today there is also political consensus at the European level that GD is the best available technology for disposing of high-level waste and spent fuel. However, this does not mean
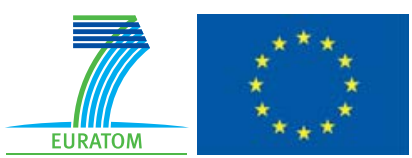

The publication of this research has been funded by the European Union's European Atomic Energy Community's (Euratom) Seventh Framework programme FP7 (2007-2013) under grant agreements $n^{\circ} 249396$, SecIGD, and $n^{\circ} 323260$, SeclGD2. 
that this technical concept is no longer controversial (see for example TNS, 2008; Wallace, 2010).

The European Commission (EC) Directive also states that national programmes need to include research, development and demonstration activities to implement solutions for the management of spent fuel and radioactive waste. It also indicates that "scientific research and technological development supported by technical cooperation between actors may open horizons to improve the safe management of spent fuel and radioactive waste". The concept of GD has developed, and will continue to do so, not only because of evolutions in scientific knowledge, but also as a consequence of debates on how to integrate this technology into society. A clear example of this is the introduction of concepts such as 'retrievability' in Switzerland and 'reversibility' in France (NEA, 2011). It demonstrates the need to think about GD not as a technology designed by scientists and experts, but as a sociotechnical concept of which the meaning and characteristics are negotiated and value laden.

At the European level, exchanges between responsible national authorities regarding $R \& D$ on GD are stimulated by the IGD-TP (Implementing Geological Disposal Technology Platform). The IGD-TP is one of several European Technology Platforms (ETPs) that have been set up by the EC as mechanisms for creating knowledge and advising on research and development (R\&D) policy in a specific domain. Most ETPs have established Member State Mirror Groups in order to provide an interface between developments at the ETP level and complementary activities at the national level. The task of the Mirror Group is to "bring the vision of the ETP and its stakeholders closer to the Member States and regions in order to facilitate cooperation" (IDEA, 2008). In the case of the IGD-TP, radioactive waste management (RWM) organizations argue that there is no need to have mirror groups or national technology platforms because the agencies themselves already represent Member States.

In this paper, which is a result of the InSOTEC project (InSOTEC is a Euratom $7^{\text {th }}$ Framework Programme project which aims to generate a better understanding of the complex interplay between the technical and the social in radioactive waste management and, in particular, socio-technical challenges in the implementation of geological disposal; further information is at www.insotec.eu), we explore to what extent there are such national platforms that broaden interaction beyond an expert community and, for this, we map out the R\&D networks around R\&D programmes on RWM, and particularly, GD (here, the definition of an R\&D programme is as follows: a structured documented programme on research on radioactive waste management, either as a targeted programme on this specific subject, or as a dedicated component of a larger R\&D framework programme. Such a structured programme on radioactive waste management can be relatively small in size or quite elaborate, issued under the responsibility of one specific organization, or piloted by a number of bodies of public or private nature). We focus on identifying those elements that provide insights into processes involving some degree of inter- and transdisciplinarity in setting up the R\&D programme. Our argument is that the way GD is framed by the research and policy community has important implications for the processes of developing and governing a technology. The aim is to avoid socially undesirable technological configurations before it is too late and problems regarding the political acceptance of a certain technology become manifest. For this reason, we aim to provide empirical evidence that explains how R\&D programmes are currently being developed and to what extent they have a concern for the need to integrate societal considerations. We will explore patterns of collaboration on RWM at the national level and gain insights into the degree to which social science researchers and other stakeholders collaborate and have an impact on the design of research programmes. First we lay out the theoretical assumptions and clarify how we understand key concepts such as inter- and transdisciplinarity. Next, we will unfold our case selection and research methodology before continuing to the discussion of our main findings regarding the level of inter- and transdisciplinarity of national R\&D programs on RWM.

\section{Theoretical framework}

Our study is in the field of Science and Technology Studies (STS), which sheds light on how science and technology shape culture, values and institutions and how such factors shape science and technology. STS scholars argue that knowledge generation is not a top-down activity through which scientists define, interpret and solve problems but rather it is co-produced through processes of symmetrical collaboration between researchers and other people concerned (Bijker et al., 1987; Jasanoff, 2006). This mode of knowledge 
production requires going beyond academic boundaries and disciplinary research and endorses interaction between the academic sphere, policy institutions and civil society.

Real-world problems do not come in disciplinaryshaped boxes (Jeffrey, 2003). In recognition of this fact, interdisciplinary programmes have been developed with the aim of overcoming gaps and inadequacies in the disciplines. Inter- and transdisciplinarity move beyond the academic disciplines and involve new ways of working, interacting and collaborating with different professionals or stakeholders. The need to support interdisciplinary and transdisciplinary research in the area of nuclear fission technology and to better recognize the concerns of people through research prioritization is also recognized by the EC (2013). However, what is specifically meant and understood by inter- and transdisciplinarity should be clear from the outset. Interdisciplinarity in an R\&D programme is used throughout this paper as an attempt to integrate or synthesize perspectives from different disciplines in a cooperative manner within the framework of a national $R \& D$ programme. Transdisciplinarity primarily refers here to an approach oriented to bring research closer to the concerns of citizens by engaging them in the identification of research problems and consequently, attempting to better respond to complex real world problems. This paper considers the role of social sciences and of stakeholder involvement in the process of agendasetting for R\&D on RWM, but does not aim to question or facilitate the implementation of GD.

There are important barriers to interdisciplinary programmes, of which the differing of perspectives and methods between different scientific disciplines and a lack of sufficient autonomy are the most important (Augsburg, 2006). Bruce et al. (2004) identified problems in European research programmes regarding the interaction with stakeholders because of the different needs and concerns of stakeholders and researchers. For Dini et al. (2011), the "impossibility of interdisciplinary research is associated with the impossibility of ultimate theoretical unification among disciplines based on contradictory epistemological foundations". Yet, they argued that it is possible and valuable for the different disciplinary perspectives to collaborate and appreciate new ways of thinking about problems that are usually firmly rooted in discipline-specific ways of working.

'Transdisciplinary research' refers to research activity that aims to integrate "knowledge that is segmented into different scientific fields and fields of practice" (Bergmann et al., 2005) and that is "characterised by a process of collaboration between scientists and non-scientists on a specific real-world problem" (Walter et al., 2007). Transdisciplinary research shares methods with the field of STS, it incorporates stakeholder engagement in the problem definition, the definition of objectives and approaches, and in the research itself to foster "socially robust knowledge" (Nowotny et al., 2001). Policy documents (e.g. ONDRAF/NIRAS, 2010) show how awareness has been growing among implementers that demonstrating a robust solution for geological disposal through R\&D will also need to address criteria relating to societal stability besides guaranteeing technical certainty. Thus, during transdisciplinary processes, stakeholders are actively and constantly involved in the process of producing knowledge through mutual learning among researchers and themselves. The evaluation of transdisciplinary research projects indicates that one of the main impacts of these processes is the building of networks between the participants (Bergmann et al., 2005; Walter et al., 2007).

Research concerning RWM was traditionally dominated by technical knowledge and when conflict over the siting of facilities arose, social science research entered into the debate. Blowers and Sundqvist (2010) argued that the two fundamental problems of radioactive waste - safety and siting - have been dealt with by different means. While the safety of deep GD has been the predominant domain of science and engineering, the acceptability of and participative approaches to siting disposal facilities has been the domain of the social sciences. Within this field of social-science research on high-level nuclear waste, Solomon et al. (2010) identified three overlapping time periods. In the latter, since the mid-1990s, research has largely dealt with public participation, political systems and international solutions, as well as risk perception and siting conflicts. Ethical issues have also been considered. Solomon et al. (2010) proposed that "social scientists should continue to raise broader and moral questions about nuclear technology" and should aim towards an integrated approach that develops a cross- or transdisciplinary methodology. Despite the need to open up the techno-scientific hypothesis of deep GD to a broader range of stakeholders, the precise role of the social sciences remains unclear. Stauffacher and Moser (2010) demonstrated the difficulties of developing mutual understanding in interdisciplinary teams involved in nuclear waste governance. 
Epistemological and structural differences between the technical and the social sciences are so fundamental that it is unlikely that a new epistemic community will be able to develop.

Table 1 attempts to identify some of the elements of inter- and transdisciplinarity that are explored in the process of designing and formulating research programmes. The inter- and transdisciplinary elements in the review and evaluation phase of the programme have not been addressed here.

\section{Methodology and case selection}

Several methods were used to obtain an in-depth perspective into the R\&D programmes: expert interviews, a survey and document analysis. First of all, we drew from a network of country experts to identify those R\&D programmes that would be of most interest to us. We then conducted a survey as a starting point to assess the inter- and transdisciplinary nature of R\&D programmes on RWM. The aim was not to conduct a random survey but to learn from the experience of ongoing programmes. For this reason, we sent the survey to at least three people representing $R \& D$ coordinators at the following organizations: the implementer, the regulator and an academic institution. In a few cases (France, Switzerland and the Netherlands), the survey was complemented with follow-up telephone interviews with those who had responded to the questionnaire. In these cases, the interviews allowed us both to crosscheck the output from the survey but also to refine our understanding on certain key research questions. Finally, we also analysed documents such as research strategies, programme evaluations, etc. In addition, email exchanges with academics involved in the national $R \& D$ programme and in the InSOTEC project also helped to clarify some aspects of the programmes.

On the basis of the survey results and desk research, we identified twelve national R\&D programmes which seem to encourage, at the conceptual level, some degree of integration between disciplines and which attempt to draw on collaborative approaches that integrate research from various disciplines with the knowledge of stakeholders in society. (The case selection does not include R\&D programmes that involve only technical research, or development projects such as the NAGRA R\&D programme, the Mont Terri research programme in Switzerland or the Posiva R\&D plan. Other initiatives such as the Dialogue Platform Energiewende have also been disregarded.) We selected for this paper nine R\&D programmes in seven countries to show the variety of approaches regarding inter- and transdisciplinarity. From our experience we expect that in some of the most advanced countries regarding geological disposal programmes, there is an institutional recognition of the important role of social sciences and humanities. In contrast, countries with less advanced programmes tackle geological disposal primarily as a technical activity and social science is not visible in their $R \& D$ programmes (see Table 2). For this purpose, we chose not to address Central and Eastern European programmes here as these countries usually lack structured R\&D programmes in relation to geological disposal, particularly in the field of socialsciences research.

Even within this group of seven countries a significant level of heterogeneity remains. There are those countries with advanced GD programmes such as France, Finland and Sweden, but also countries where the search for suitable sites is progressing (such as Belgium and Switzerland) or is under review (the UK). Finally, in the Netherlands, centralized interim storage is planned to last for at least 100 years.

\section{Interdisciplinarity in R\&D programmes}

Firstly, we observe that the social and political sciences seem to be substantially represented in all $\mathrm{R} \& \mathrm{D}$ programmes and, to a lesser extent, the humanities, economics and law. However, as mentioned above, R\&D programmes are structured in different ways. Some countries have developed specific social science $R \& D$ programmes, as in Sweden and Switzerland, while in others, the social sciences are part of a larger programme covering different topics. The way in which these programmes are structured from the outset and the motivations for developing social science research programmes or focusing on specific research topics can be seen as a factor that may enhance or discourage interdisciplinary research, just as well as it may set the boundaries on the topics and parameters of interest, dictate the methodological approaches and predetermine to a large extent the outcomes of the research.

In Switzerland, the Expert Group on Disposal Concepts for Radioactive Waste (EKRA) concluded in 2002 that Switzerland's scientific and technical research into radioactive waste disposal was at a very high level, but there was room for 
TABLE 1. Elements of inter- and transdisciplinarity in R\&D programmes on geological disposal.

\begin{tabular}{|c|c|c|}
\hline $\begin{array}{l}\text { Phases of the } \\
\text { research } \\
\text { programme }\end{array}$ & Elements of interdisciplinarity & Elements of transdisciplinarity \\
\hline $\begin{array}{l}\text { Design and } \\
\text { formulation }\end{array}$ & $\begin{array}{l}\text { - Integration of socioeconomic and natural } \\
\text { sciences } \\
\text { - Explicit acknowledgement of the value of } \\
\text { interdisciplinarity } \\
\text { - Consultation with researchers from } \\
\text { different disciplines on framing the research } \\
\text { agenda } \\
\text { - Balance between social science and } \\
\text { natural science research projects }\end{array}$ & $\begin{array}{l}\text { - R\&D programme formulated as an open issue, not } \\
\text { completely closed } \\
\text { - Explicit acknowledgement of the value of } \\
\text { involving a wide range of stakeholders in society in } \\
\text { the R\&D process } \\
\text { - Consultation with other forms of knowledge (non- } \\
\text { scientific) on framing the research agenda }\end{array}$ \\
\hline
\end{tabular}

improvement with respect to social issues (EKRA, 2002). The report also indicated that independent state-funded research was required alongside the research activities defined by Nagra (EKRA, 2002). As a consequence, there is now a separate $R \& D$ programme focusing on the social sciences that is promoted and led by the Ministry, SFOE. However, such a strict separation did not follow the recommendations of the EKRA committee, which had suggested that a research programme should be set up independently of NAGRA with a focus on both the social sciences and the technical and natural sciences (EKRA, 2002). The separation of responsibilities between SFOE, which takes the lead on the political aspects, and NAGRA, controlling the technical side, can be considered to form a potential obstacle to combining the technical and societal dimensions when designing solutions (Minhans and Kallenbach-Herbert, 2012).

Other programmes, such as NEEDS in France or KYT2014 in Finland, were conceived and presented as interdisciplinary from the outset. NEEDS was traditionally organized as a large national industrial project from a technical point of view and the social sciences were introduced later - when the project was almost finished - to achieve 'social acceptance'. Nowadays, this has evolved and social sciences are predominantly involved in one of the seven integrated projects focusing on 'nuclear risk and society', which involves historians, media, sociologists and others. Nevertheless, interdisciplinarity remains hard to achieve in such a project. It is reported that one of the main challenges is now to develop a more holistic view to include the social sciences at the very beginning of any project, rather than bringing them in at the end, as used to be the case, merely to obtain the 'public's acceptance' of the technology. Other obstacles to working in an interdisciplinary environment, according to interviews undertaken for this project, are related to the perceived unfeasibility of some natural scientists working with social scientists mainly because of their epistemological and ethical viewpoints.

A similar evolution can be observed with regard to KYT2014. In the first two years, research focused on monitoring the attitudes and opinions of the inhabitants of Eurajoki and surrounding municipalities regarding the disposal of nuclear waste as well as the need for and methods of accessing information (MEE, 2011). The current KYT2014 programme explicitly delineates an area of "sociological research related to nuclear waste management" with the aim "to support decisionmaking and the related preparations". Apart from the analysis of the viewpoints of various actors involved in nuclear waste, the programme also points out two interesting themes for sociological research: ethical debate and long-term duration. However, there is a need to promote social science projects among social scientists, as suggested by the KYT2014 review report: “... there is a need for some action to attract more interest in the social scientist community with respect to NWM [nuclear waste management], to look for unexamined linkages between NWM and other societal issues of interest to social science investigators." (MEE, 2013).

Probably even more meaningful for the integration of social sciences in these R\&D programmes, is the topics they work on. In most countries, 'perception and communication' is the main social science 


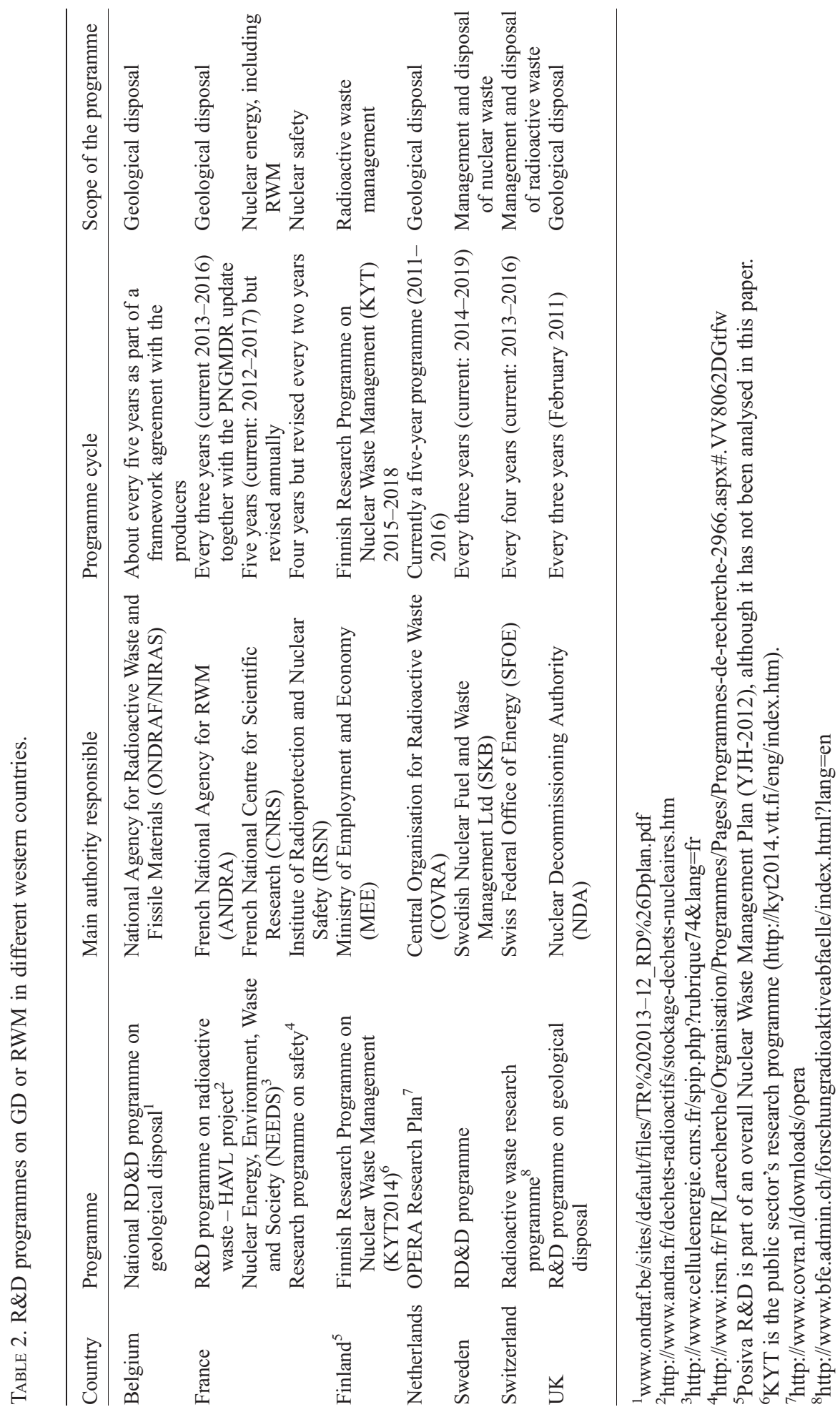


research topic, while in some cases public participation is also considered, but almost no attention is paid to decision-support methodologies.

At first sight, fewer topics seem dedicated to an analysis of the mutual shaping of technology and society or to the sociotechnical nature of RWM or GD, at least explicitly. We could argue that some social science topics seem to offer potential for an integrative treatment of the social and the technical, such as reversibility and retrievability, safety, monitoring and knowledge transfer. It is interesting here to explore the reasons why these 'sociotechnical topics' (instead of purely technical or purely social sciences topics) are included in the R\&D programme. For instance, in France, the focus on reversibility and retrievability emanated from civil society (Aparicio, 2010) and the National Waste Act in 1991 changed the focus of the research programme to introduce the study of reversibility and the impact of waste retrievability. In the context of RWM, Lehtonen (2010), borrowing Barthe's concepts of 'reversibilization' and 'irreversibilization', argued that there are signs of an opening up of RWM policy in France to new actors and new options. However, it is not clear whether this opening up is part of a 'staged process whereby political decisions progressively lead towards final GD, with R\&D perceived by policymakers as an interim solution on the path towards such irreversibilization' or to 'subsequent moments of 'opening up' and reappraisal of alternatives' (Lehtonen, 2010). It is interesting to mention here that in the case of France, the presence of a sociologist, who holds a PhD in Science and Technology Studies, in charge of Social Sciences and Humanities at the R\&D Division of ANDRA inevitably influences the research topics of the R\&D programme in France.

\section{Transdisciplinarity in R\&D programmes}

Consultation on $R \& D$ is rarely undertaken on a formal and regular basis or as a process in itself. Rather, in most of the countries, consultation with stakeholders does not take place strictly in the framework of the R\&D programme but informally as part of the broader consultation of the overall national RWM programme undertaken by the responsible organization. Such was the case in Switzerland, for example, in the development of the Sectoral Plan or in Belgium where the implementer, NIRAS, organized a number of public consultations during the development of its Waste Plan. The integration of societal conditions following from these consultations, such as provisions for retrievability, naturally also affects the research orientation. However, as in most other countries, the status of R\&D was not subject to specific consultation. An exception would be the Netherlands, where there was broad consultation with universities and research organizations in the drafting of the OPERA programme in the framework of the Network for Geological Disposal of Radioactive Waste (NORA).

A second recurring practice across the countries is that consultation on R\&D is mostly oriented towards local stakeholders. As SKB states in its R\&D programme: "the main target group for the [social science] research programme is local and national decision-makers" (SKB, 2013). The municipalities involved in the siting programme, apart from the safety authority, also have a formal role in reviewing the SKB R\&D programme. The same goes for Switzerland, where SFOE focuses on involving stakeholders from the selected sites/ regions through the regional conferences that are set up in each of the potential hosting regions. Due to this local scope most of the dialogue is oriented towards socioeconomic issues such as compensation measures, rather than on scrutinizing scientific or technical R\&D.

Another observation regarding stakeholder involvement is that, in general, sociological research topics gain salience as the programme approaches the site-selection process, precisely to support and assist the search for a socially acceptable repository site. Afterwards, when the site has been selected, as is the case in Finland and Sweden, social science research again seems to become marginalized. In the case of Sweden, the SKB social science research programme, with earmarked funding to address social issues, was terminated just before the new phase of review of the license application began. At present, in its current RD\&D programme for the period 20142019, SKB states that it "does not intend at present to initiate a new research programme" on social sciences due to the current review of the license applications, but "is prepared to fund research projects of a social-scientific nature within areas deemed of importance for SKB's activities, particularly in the municipalities of Oskarshamn and Östhammar" (SKB, 2013).

Finally, one way to promote dialogue and improve the quality of debate on $R \& D$ is by developing a publicly available inventory of questions raised and answered by stakeholders. In 
Switzerland, this is implemented by the Technical Forum on Safety (TFS), which was set up in 2009 to discuss technical and scientific issues raised by NGOs, siting regions and communities, cantons, etc. Similarly, in the UK, the Issues Register, developed by the NDA, provides opportunities for all who take an interest in geological disposal to influence the work programme of the NDA and provide input into their approach by raising an issue or concern related to the implementation of geological disposal, providing comments or expressing views on the overall process or approach. These issues can include views on different aspects of the research programme, additional research needs, etc.

\section{Conclusions}

In this paper we have argued that the evolving knowledge and changing societal expectations surrounding the design and implementation of a radioactive waste facility demands an understanding of 'the social' and 'the technical' which moves beyond the traditional compartmentalized scientific knowledge. The traditional approach based on the division between the 'technical' and the 'social' has important effects for the understanding of GD and the challenges its implementation encounter. We observed that the inter- and transdisciplinary character of national $R \& D$ programmes is strongly influenced by the great variation in the structuring of $R \& D$ responsibilities. Failure to draw upon social-science knowledge from the beginning could result in weakly designed and underperforming R\&D programmes. As a consequence, the social becomes empirically and analytically separated from the technical and this separation may prevent a deeper understanding of the nature of these relationships.

In some cases, R\&D programmes are self-named 'interdisciplinary' but the problem is mostly framed in techno-scientific terms and social sciences remains a minor part of a whole programme dominated by technical concerns, impeding the possibility to challenge technical solutions. The social sciences are not seen as fundamental in the formation of policy advice, and social scientists are generally only involved in understanding and removing the societal barriers which appear to impede progress towards implementing a predetermined technological solution. Thus, social scientists are primarily involved in research on public perceptions, communication and participation practices. The latter may also be a reason for the reported difficulty of attracting social scientists to engage in research in geological disposal. From our study it appears that interdisciplinary dialogue is only rarely realized on potentially fruitful topics for integrative research, such as risk assessment or safety-case development.

Despite growing recognition of the potential value of taking an interdisciplinary approach to complex problems, existing institutional research frameworks often make it difficult to foster such approaches. We suggest the need for incremental changes towards setting up research partnerships tailored to address scientific and societal changes in innovative ways. The recently set up ENTRIA project (Disposal Options for Radioactive Residues: Interdisciplinary Analyses and Development of Evaluation Principles) in Germany demonstrates that there is an active interest from researchers from different disciplines to integrate both technical and social science research.

More challenging to current ways of thinking and working is the notion of transdisciplinary research; research that provides opportunities for meaningful involvement of stakeholders. This would require not only the willingness of research institutions and individual researchers to venture beyond the frontiers of their own disciplines in order to address complex questions of societal relevance, but also the willingness of stakeholders and citizens to engage in a sustained manner with the technical problems and repertoires of the R\&D communities. Based on the findings in this paper, we see two channels for addressing this challenge. First, by including social science research as an integral part of, rather than a mere adjunct to, conventional techno-scientific analysis in $R \& D$ programmes on geological disposal. Secondly, by exploiting the opportunities provided by the R\&D agenda-setting phase for fostering collaboration between different types of knowledge.

This concern with the production of knowledge and of the socio-technical strategies and solutions required to address the problems posed by longlived higher-activity radioactive waste emphasizes the necessity of also viewing the problem posed by geological disposal as being fundamentally 'sociotechnical' in nature.

\section{References}

Aparicio, L. (editor) (2010) Making Nuclear Waste Governable. Deep Underground Disposal and the Challenge of Reversibility. Springer/ANDRA. 
Augsburg, T. (2006) Becoming Interdisciplinary: An Introduction to Interdisciplinary Studies. Kendall/ Hunt Publishing, Dubuque, Iowa, USA.

Bergmann, M., Brohmann, B., Hoffmann, E., Loibl, M. C., Rehaag, R. Schramm, E. et al. (2005) Quality Criteria of Transdisciplinary Research. A Guide for the Formative Evaluation of Research Projects. Institute for Social-Ecologic Research, Frankfurt am Main, Germany.

Bijker, W., Hughes, T. and Pinch, T. (1987) The Social Construction of Technological Systems. MIT Press, Cambridge, Massachusetts, USA.

Blowers, A. and Sundqvist, G. (2010) Radioactive waste management - technocratic dominance in an age of participation. Journal of Integrative Environmental Sciences, 7, 149-155.

Bruce, A., Lyall, C., Tait, J. and Williams, R. (2004) Interdisciplinary integration in Europe: the case of the Fifth Framework Programme. Futures, 36, 457-470.

COVRA (2011) OPERA: Research Plan. OPERA-PGCOV004, July 2011.

Dini, P., Iqani, M. and Mansell, R. (2011) The (im) possibility of interdisciplinarity: lessons from constructing a theoretical framework for digital ecosystems. Culture, Theory and Critique, 52, 3-27.

EC [European Commission] (2013) 2012 Interdisciplinary Study. Benefits and limitations of nuclear fission for a low-carbon economy. Defining the priorities for Euratom fission research and training (Horizon 2020). Compilation of the experts' reports. Background to the synthesis report.

EKRA (2002) Contribution to a strategy on radioactive waste management in Switzerland (Beitrag zur Entsorgungsstrategie für die radioactiven Abfälle in der Schweiz' in German). Authors: W. Wildi, D. Appel, M. Buser, F. Dermange, A. Eckhardt, P. Hufschmied, H.R. Keusen and M. Aebersold, October 2002.

IDEA (2008) Evaluation of the European Technology Platforms (ETPS). Idea consult. Report commissioned by the EC - DGBUDG, Brussels.

Jasanoff, S. (editor) (2006) States of Knowledge. The CoProduction of Science and Social Order. Routledge, New York.

Jeffrey, P. (2003) Smoothing the waters: observations on the process of cross-disciplinary research collaboration. Social Studies of Science, 33, 539-562.

Lehtonen, M. (2010) Opening Up or Closing Down Radioactive Waste Management Policy? Debates on
Reversibility and Retrievability in Finland, France and the United Kingdom. Risks, Hazards \& Crisis in Public Policy, 1 (4), Article 6.

MEE (2011) KYT 2010 Finnish Research Programme on Nuclear Waste Management 2006-2010. Final report. Ministry of Employment and the Economy. Energy and the Climate 26/2011.

MEE (2013) KYT 2013 Review Report. Ministry of Employment and the Economy. Energy and the Climate 10/2013.

Minhans, A. and Kallenbach-Herbert, B. (2012) Identifying remaining socio-technical challenges at the national level. InSOTEC working paper, Germany.

NEA (2011) Reversibility and Retrievability for the deep disposal of HLW and Spent Fuel. Final report of the NEA R\&D Project. NEA/RWM/R(2011)4. OECD, Paris.

Nowotny, H., Scott, P. and Gibbons, M. (2001) ReThinking Science: Knowledge and the Public in an Age of Uncertainty. Polity Press, Cambridge.

ONDRAF/NIRAS (2010) Strategic Environmental Assessment (SEA) over het afvalplan van NIRAS. NIRAS 5249-506-068, June 2010.

SKB (2013) RD\&D Programme 2013. Programme for research, development and demonstration of methods for the management and disposal of nuclear waste. Technical report TR-13-18. September 2013.

Solomon, B.D., Andrén, M. and Strandberg, U. (2010) Three decades of social science research on high-level waste: Achievements and future challenges. Risks, Hazards \& Crisis in Public Policy, 1 (4) Article 2, 13-47.

Stauffacher, M. and Moser, C. (2010). A new 'epistemic community' in nuclear waste governance? Theoretical reflections and empirical observations of some fundamental challenges. Catalan Journal of Communication and Cultural Studies, 2, 197-211.

TNS (2008) Attitudes to Radioactive Waste - Special Eurobarometer 297. European Commission, Brussels.

Wallace H. (2010) Rock Solid? A scientific review of geological disposal of high-level radioactive waste. GeneWatch UK: report commissioned by Greenpeace International.

Walter, A.I., Helgenberger, S., Wiek, A. and Scholza, R. W. (2007) Measuring Societal Effects of Transdisciplinary Research Projects: Design and Application of an Evaluation Method. Evaluation and Program Planning, 30, 325-338. 